\title{
The Research of Undergraduate Marketing Talents Cultivation Mode Under the Background of Guangdong-Hong Kong-Macao Greater Bay Area
}

\author{
Zhuang Ming Jie, Wang Zi Ling, Chang Che Chang* \\ Business Administration Department, Guangzhou Huashang College, Guangzhou, China
}

Email address:

1794298328@qq.com (Chang Che Chang)

${ }^{*}$ Corresponding author

\section{To cite this article:}

Zhuang Ming Jie, Wang Zi Ling, Chang Che Chang. The Research of Undergraduate Marketing Talents Cultivation Mode Under the Background of Guangdong-Hong Kong-Macao Greater Bay Area. Science Innovation. Vol. 9, No. 1, 2021, pp. 26-31.

doi: 10.11648/j.si.20210901.15

Received: January 20, 2021; Accepted: March 4, 2021; Published: March 12, 2021

\begin{abstract}
The construction of the Guangdong-Hong Kong-Macao Greater Bay Area has a major impact on the cultivation of applied undergraduate marketing talents. The target of this paper is for marketing talents with new media marketing application capabilities. Research explores the existing problems of the current model from different perspectives such as the distribution of existing universities, curriculum, teacher structure, teaching mode... and so on. Focusing on the strategic positioning of the Bay Area to create a vibrant world-class urban agglomeration, in-depth cooperation between the Mainland and Hong Kong and Macao. The new model of applied undergraduate marketing talent training should be dedicated to building a marketing curriculum system that matches the new industrial capabilities of the Bay Area. "Institute + new industry + marketing" "integrated practice teaching base for production, teaching and research, the model for promoting innovative practice in competitions", and the cooperation between Guangdong, Hong Kong and Macao colleges and universities to explore a teaching model for running schools. The talents cultivated in the Guangdong-Hong Kong-Macao Greater Bay Area should have our own characteristics, which are: international, digital, and innovative talents. Thus, colleges and universities in this district should create such talents to sprout and thrive here. And we also want to build an international platform in the Greater Bay Area to attract talents from all over the world to work here.
\end{abstract}

Keywords: Guangdong-Hong Kong-Macao Greater Bay Area, Undergraduate, Marketing Training Model, Technology Innovation

\section{粤港澳大湾区应用型本科营销人才培养模式研究}

\author{
庄明杰, 王子玲, 张哲彰" \\ 广州华商学院工商管理系, 广州, 中国 \\ 邮箱 \\ 1794298328@qq.com（张哲彰）
}

摘要: 䁖港澳大湾区建设对应用型本科营销人才培养具有重大影响。为适应大湾区国际科技创新中心的发展需求, 应
用型本科营销人才培养应以培育具有国际视野、广府情怀、新型产业领域新媒体营销能力的应用型营销人才为目标。
聚焦湾区打造充满活力的国际级内地与港澳深度合作示范区的战略定位。研究从不同的角度探讨了当前模式存在的问
题, 例如现有大学的分布, 课程设置, 教师结构, 教学模式...等。应用型本科营销人才培养模式应致力于构建与湾区
新型产业能力相匹配的市场营销课程体系、“学院+新型产业+市场营销”产学研用一体化实践教学基地、以赛事促进创 
新实践的模式、粤港澳三地高校合作探索办学的教学模式。粤港澳大湾区培育的人才应该有自己的特色, 这个特色就 是: 国际化, 数字化、创新型的人才。是故, 本区高校应该创造这类人才在此萌芽茁壮, 而且我们也要在大湾区打造 一个国际化的平台, 吸引世界各地的人才来此工作。

关键词：粤港澳大湾区，科技创新，应用型本科，营销人才培养模式

\section{1. 引言}

我国国务院于 201902 颁发的《粤港澳大湾区发展规划 纲要》提出, 粤港澳大湾区的战略定位是构建具有全球影 响力的国际科技创新中心。要求我们要瞄准世界科技创新 产业发展前沿, 加强创新平台建设, 大力发展新技术、新 产业、新业态、新模式, 加快形成以创新为主要动力和科 技智能化支撑的经济体系。此外, 还要全面推进创新改革 试验, 发挥粤港澳科技研发与科技产业创新优势, 扫除影 响创新要素自由流动的瓶颈和制约, 激发企业创新主体活 力，建成全球科技创新高地。[1]

科技创新需要优秀的商业模式, 商业模型创新需要科 技创新型产业的支撑。唯有结合高素质的科技人才和复合 型市场营销人才才是科技产业创新的主力, 才能积累湾区 全球科技创新目标的核心竞争力。因此, 大湾区建设的科 技产业创新实践, 优化应用型市场营销人才的培养模式, 具有重要的现实需求和实践意义。

\section{2. 粤港澳大湾区建设对营销人才的需求}

粤港澳大湾区作为全球“四大湾区”之一, 经济发展迅速, 大湾区内产业合作分工紧密。香港、澳门、深圳、广州、佛 山、东莞、珠海的经济发展规模和发展速度都比较快。

粤港澳大湾区2019年GDP合计为 11.59 万亿元。以经济 总量来看, 深圳市在 2019 年完成GDP接近 2.7 万亿元人民币, 其中, 计算机、通信和其他电子设备制造业同比增长 $5.5 \%$, 电气机械和器材制造业同比增长 $7.1 \%$, 通用设备制造业同 比增长 $7.2 \%$; 香港地区在 2019 年完成GDP为 28681.71 亿港 元，折合 25250.73 亿元人民币; 广州市完成GDP为 23628.6 亿元, 在大湾区内排第三名; 澳门地区在2019年完成GDP 为4346.70亿澳门元, 折合 3715.54 亿人民币, 虽然经济总量 不占优势, 但由于澳门人口只有 67.6 万, 其人均GDP超过 了 50 多万元人民币（约 8 万美元），领先幅度较大; 佛山市 GDP突破 1 万亿元, 达到10751.02亿元, 成为大湾区内第四 个“万亿元城市”; 东莞市完成GDP已接近9500亿元; 惠州 市完成GDP为4177.41亿元, 珠海市完成GDP为3435.89亿元, 江门市完成GDP为 3146.64 亿元, 中山市完成GDP为 3101.1 亿元，肇庆市完成GDP为 2248.8 亿元。

\section{1. 应用型本科营销人才需求持续增加}

根据广东省委、省政府印发《广深科技创新走廊规划》 [13]，广深科技走廊涉及广州、深圳、东莞。构建科技创 新核心要素, 打造全球顶尖科技创新产业创新平台。其中 广州集聚了广东省众多的大学和科研院所, 深圳则在应用 研发领域集聚了一批高成长性的创新型企业, 以东莞制造
业的优势, 把广州、深圳两头通过一个“廊道”连起来, 让 这个区域的创新要素很好地流动和聚集。

又在2018年8月, 粤港澳大湾区建设领导小组会议提 出, 建设“广州-深圳-香港-澳门”科技创新走廊。这样广深 科创走廊可延伸至港澳, 最终形成粤港澳大湾区的创新模 式。从而推进“广州一深圳一香港一澳门”科技创新走廊建 设，探索有利于人才、资本、信息、技术等创新要素大湾 区流动和融通的政策举措, 共建粤港澳大湾区科技产业国 际化创新平台。这也是将粤港澳大湾区建设成为我国创新 型科技的发展片区[15]。

构建大湾区开放型区域协同创新共同体, 打造高水平科 技创新平台, 优化大湾区的创新环境, 这些都有赖于广东、 香港与澳门三方的共同努力和深度合作。具体来看, 香港有 全球排名靠前的高校, 全球大学 100 强中有 5 所在香港, 香港 高等院校的基础研究实力雄厚; 深圳与广州地区, 具有强大 的产业基础研发以及完善的产业链条, 产业转化速度快; 东 莞、佛山、肇庆等地区, 具有强大的制造生产能力[14]。因 此, 在构建大湾区区域协同创新共同体时, 就必须透过知识 外溢手段及产业分工，以调动整个湾区经济的协同发展。

截止到2019年12月，大湾区企业总数达到738.9万户。 2014 年至 2019 年大湾区 GDP 规模从 8.172 万亿元增长到 11.59 万亿元, 增长速度达到 $7.56 \%$, 是全国经济最活跃的 地区。同时大湾区科技产业仍存在产能过剩、产业发展趋 同、供给与需求结构不平衡问题, 经济增长内生动力有待 增强。科技创新企业市场成长的吸引力和激烈的市场竞争, 这也促使科技创新企业对复合型市场营销人才需求规模 大幅度成长。[3]

\section{2. 粤港澳大湾区内高素质应用型营销人才需求缺口大}

据《2019年粤港澳大湾区人力资源白皮书》报告研究 显示, 粤港澳三地最难招聘包括产品销售专员、产品销售 经理、零售经理等市场营销类岗位。尤其是闯新型科技产 业需要的复合型市场营销人才更是稀缺资源。

粤港澳大湾区背景下, 企业对应用型本科营销人才需 求的新增长点主要集中在科技创新产业领域, 科技创新产 业具有在技术上技术领先、模式创新、差异定位等特点, 市场定位与技术创新有关，例如技术创新的层次、技术赋 能的领域、技术创新带来的用户利益等; 科技产业的企业 开展差异化营销模式的特点明显。以过去纯粹市场营销理 论、市场营销方法为主要教学内容的传统营销人才培养方 案已经无法满足科技创新企业营销的需求。[4]

因此，如何优化应用型本科市场营销人才培养模式， 为大湾区建设输送具有敏锐市场营销知识、熟悉现在及未 来科技发展趋势、具有国际观、创造性思维的高素质应用 型市场营销人才, 以助力粤港澳大湾区成为国际科技创新 中心做出应有的贡献。 


\section{3. 构建粤港澳大湾区创新科技产业对市场营销 人才培养模式的意义}

\section{1. 粤港澳大湾区科技产业创新品牌建设对应用型本科 市场营销人才培养目标的影响}

据2019年《财富》世界500强企业分析，粤港澳大湾 区有19家企业上榜，在这些企业(不含香港)中，民营企业
有7家，占比超过五成。中国平安领头羊是排名第29位, 华为排名第61位居次, 最后一位是排名第451位的太平保 险集团。其中华为、雪松、腾讯等科技创新民企走势强劲, 影响力已扩展到全球, 向世界展现出粤港澳大湾区民营经 济蓬勃发展的活力。[5]

表1 2019年粤港澳大湾区GDP分析。

\begin{tabular}{lll}
\hline 城市 & GDP & 实际增速 \\
\hline 深圳 & 26972.09 & $6.70 \%$ \\
香港 & 25250.73 & $-1.20 \%$ \\
广州 & 23628.60 & $6.80 \%$ \\
佛山 & 10751.02 & $6.90 \%$ \\
东莞 & 9482.50 & $7.40 \%$ \\
惠州 & 4177.41 & $4.20 \%$ \\
澳门 & 3715.54 & $-4.70 \%$ \\
珠海 & 3435.89 & $6.80 \%$ \\
江门 & 3146.64 & $4.30 \%$ \\
中山 & 3101.10 & $1.20 \%$ \\
肇庆 & 2248.80 & $6.30 \%$ \\
合计 & 115910.22 & \\
\hline
\end{tabular}

资料来源: 本研究整理

表2 2019年粤港澳大湾区世界500强企业名单。

\begin{tabular}{|c|c|c|c|c|}
\hline 排名 & 上年排名 & 公司名称(中英文) & 营业收入(百万美元) & 总部所在城市 \\
\hline 29 & 29 & 中国平安保险（集团）股份有限公司（PING AN INSURANCE） & 163597.4 & 深圳 \\
\hline 61 & 72 & 华为投资控股有限公司（HUAWEI INVESTMENT \& HOLDING） & 109030.4 & 深圳 \\
\hline 80 & 86 & 中国华润有限公司（CHINA RESOURCES） & 91986 & 香港 \\
\hline 111 & 110 & 中国南方电网有限责任公司 (CHINA SOUTHERN POWER GRID) & 80963.6 & 广州 \\
\hline 119 & 111 & 正威国际集团（AMER INTERNATIONAL GROUP） & 76363.1 & 深圳 \\
\hline 138 & 230 & 中国恒大集团（CHINA EVERGRANDE GROUP） & 70478.9 & 深圳 \\
\hline 177 & 353 & 碧桂园控股有限公司（COUNTRY GARDEN HOLDINGS） & 57308.7 & 佛山 \\
\hline 188 & 213 & 招商银行（CHINA MERCHANTS BANK） & 55063.5 & 深圳 \\
\hline 189 & 202 & $\begin{array}{l}\text { 广州汽车工业集团（GUANGZHOU AUTOMOBILE INDUSTRY } \\
\text { GROUP） }\end{array}$ & 55037.2 & 广州 \\
\hline 212 & 240 & 联想集团（LENOVO GROUP） & 51037.9 & 香港 \\
\hline 237 & 331 & 腾讯控股有限公司（TENCENT HOLDINGS） & 47272.7 & 深圳 \\
\hline 244 & 280 & 招商局集团（CHINA MERCHANTS GROUP） & 45925.7 & 香港 \\
\hline 254 & 332 & 万科企业股份有限公司（CHINA VANKE） & 44912.6 & 深圳 \\
\hline 280 & 283 & 怡和集团（JARDINE MATHESON） & 42527 & 香港 \\
\hline 301 & 361 & 雪松控股集团（CEDAR HOLDINGS GROUP） & 40640.8 & 广州 \\
\hline 312 & 323 & 美的集团股份有限公司（MIDEA GROUP） & 39581.6 & 佛山 \\
\hline 352 & 374 & 长江和记实业有限公司（CK HUTCHISON HOLDINGS） & 35361.2 & 香港 \\
\hline 388 & 295 & 友邦保险集团（AIA GROUP） & 32369 & 香港 \\
\hline 414 & -- & 珠海格力电器股份有限公司（GREE ELECTRICAL APPLIANCES） & 30239.4 & 珠海 \\
\hline 451 & 465 & $\begin{array}{l}\text { 中国太平保险集团有限责任公司（CHINA TAIPING INSURANCE } \\
\text { GROUP） }\end{array}$ & 27485.8 & 香港 \\
\hline
\end{tabular}

资料来源：2019年《财富》世界500强企业分析

\section{2. 大湾区产业集群对应用型本科市场营销人才培养模 式的启发}

粤港澳大湾区科技创新产业规划是在新一轮科技革 命和产业变革的背景下提出来的。科技创新产业将显著改 善大湾区内传统生产模式和服务业态, 推动传统生产方式 和商业模式变革。大湾区将着力培养发展新产业、新业态、
新模式, 建设 4 类技术支撑的新支柱产业、10个重点领域 培育一批重大产业项目, 在 5 个重点领域实施一批战略性 新兴产业重大工程, 积极发展数字经济和共享经济, 推动 动漫游戏、网络文化、数字文化装备、数字艺术展示等数 字创意产业合作, 推动数字创意在会展、电子商务、医疗 卫生、教育服务、旅游休闲等领域应用,详见表3。[6] 
表3 粤港澳大湾区培养壮大战略性新兴产业一览表。

\begin{tabular}{lll}
\hline 序号 & 建设项目的类别 & 包含的具体产业 \\
\hline 1 & 新支柱产业 & 新一代信息技术、生物技术、高端装备制造、新材料技术、智能制造技术 \\
2 & 重大产业项目 & 新型显示、新一代通信技术、5G和移动互联网、蛋白类等生物医药、高端医学诊疗设备、基因 \\
3 & 战略性新兴产业重大工程 & 检测、现代中药、智能机器人、3D打印、北斗卫星应用 \\
4 & 信息消费、新型健康技术、海洋工程装备、高技术服务业、高性能集成电路 \\
5 & 数字创意产业 & 新能源、节能环保、新能源汽车等产业 \\
\hline
\end{tabular}

资料来源: 本研究整理

大湾区发展承载着以数字化、信息化、智能化为特征 的新一轮科技产业创新，对应用型本科市场营销人才培养 目标、市场营销的知识框架和创新思维能力的人才培养提 出新的需求。

\section{3. 大湾区科技创新背景下, 应用型本科市场营销人才 的需求}

要求应用型本科学生掌握的知识面的广度, 不仅要掌 握市场营销原理、市场营销管理基本技能的知识框架, 需 熟悉大湾区内大力扶持的科技创新产业的发展趋势, 同时 具备收集和分析研究科技数据和信息的能力, 从而利用科 技产业创新出现的机会制定合理有效的市场营销战略和 战术方案。[7]应用型市场营销人才也是信息化人才或数字 化人才。

因此, 大湾区建设规划对应用型本科市场营销专业人 才培养的目标、理念、知识架构和思维能力都产生深远的 影响,要求应用型本科院校在市场营销课程体系、市场营 销人才的培养模式和思维能力都需优化调整。

\section{4. 构建匹配大湾区科技产业发展需求的应用型 本科市场营销人才培养模式}

\section{1. 以科技创新产业需求为导向的应用型营销人才培养 理念}

粤港澳大湾区背景下企业对本科营销人才需求的 新增长点主要集中在科技创新产业领域, 科技创新产 业具有在技术上技术领先、模式创新、差异定位等特 点, 市场定位与技术创新有关，例如技术创新的层次、 技术赋能的领域、技术创新带来的用户利益等; 科技 产业的企业开展差异化营销模式的特点明显。以过去 纯粹市场营销理论、市场营销方法为主要教学内容的 传统市场营销人才培养方案已无法满足科技创新产业 的市场营销的需求。

为更好地服务大湾区科技创新产业的建设, 增强应 用型本科市场营销学生在科技创新企业的适应能力, 必 须改变当下应用型本科市场营销人才的培养理念, 坚持 以科技创新产业为导向, 强化应用型本科市场营销的学 生对科技创新产业的认知和对新一轮科技产业革命发 展趋势的理解, 将科技创新产业的技术创新特点融入到 市场营销理论和方法的教育过程中, 以构建能为特定的 科技创新产业企业设计有特色的市场营销人才培养模 式。[8]

\section{2. 聚焦培养科技创新产业的应用型营销人才的定位}

现有高校中的市场营销人才培养定位一般聚焦于特 定的区域、服务某种规模的企业、或者某种特定的营销能 力, 较少地聚焦于某一个具体产业, 聚焦于大湾区内重点 培育的科技创新产业则凤毛麟角。这种方式在过去短缺经 济背景下相对无差异营销, 是一种进步, 但在当前新经济 条件下科技创新产业的市场营销人才培养体系中就显得 滞后了。

科技创新产业中差异化的市场营销模式需要市场营 销人才的应用能力各有不同, 围绕科技创新产业链的特点 来构建特色的市场营销人才培养模式, 熟悉科技创新产业 的市场环境, 理解科技创新企业在市场竞争中所处的地位, 学会科技创新企业的市场细分方法, 了解科技创新企业常 用的市场营销模式, 运用当前最新的市场营销工具和方法 服务科技创新企业, 从而有效提升学生在科技创新企业的 适应能力, 为科技创新企业构建新商业模式、建立强大品 牌积累优秀的市场营销人才。

聚焦于科技创新产业内应用型市场营销人才的培养, 校企合作，科技创新型企业走入校园，让学生了解企业创 新, 产业创新, 了解科技产品创新, 增强用户视角体验, 从用户的角度开展市场营销工作, 同时具备市场营销数据 分析的能力、市场营销策划的能力, 为科技创新企业树立 良好的品牌形象。[9]

\section{3. 构建粤港澳大湾区科技创新产业市场营销强化训练 营, 培养市场营销复合人才}

构建粤港澳大湾区科技创新产业市场营销强化训练 营项目, 对有兴趣深入体验市场营销活动的所有学生开放。 每年假期在四周的时间里, 市场营销团队和学生个人将在 市场营销强化训练营提供的工作空间里, 全天候学习市场 营销核心知识和技能, 接受一对一辅导。市场营销强化训 练营不同于传统的教学模式, 它是在个性化学习的基础上 通过研讨式而不是说教式, 针对学生对科技创新产业市场 营销的需求进行高强度、集中式的市场营销思维和技能训 练。[10]从而在有限的时间内通过沉浸式的学习, 从市场 营销导师、成功的市场营销者和其他团队成员身上, 学习 如何像科技创新企业市场营销专家一样思考、学习和工作, 为未来在科技创新企业的市场营销之路夯实基础。即其学 习的重点主要是：市场营销的知识架构和技能训练、如何 做市场活动执行策划、市场调研、数字营销、计算机硬件、 网络工程基础、软件工程基础、人工智能基础以及团队工 作技能等。 


\section{4. 建立“学院+科技创新企业+市场营销”产学研用一体 化实践合作基地, 开展市场营销实习项目}

该产学研用一体化实践合作基地是一项面向应用型 本科生开放的带薪暑期实习项目，学生将在实践的企业中 与市场营销团队肩并肩工作、参与企业的市场营销项目, 并获得一对一指导, 从而深入体验市场营销过程和管理, 并确定个人是否适合科技创新企业的市场营销职业生涯。
通过参与到科技创新企业一线的市场营销带薪暑期 实习活动, 让参与人提前理解科技创新企业市场营销的运 作机制, 把学习到的市场营销知识、科技能力参与到科技 创新企业的市场营销的一线实践, 不仅提升参与人的知识 能力, 同时可以提升参与人在科技创新企业市场营销能力 和对科技技术的理解。[11]

表4 对科技创新产业市场营销培养目标的 5 大课程体系。

\begin{tabular}{|c|c|c|c|c|c|c|}
\hline \multicolumn{7}{|c|}{ 适应大湾区科技创新产业的应用型本科市场营销人才培养目标的能力细分 } \\
\hline & 学期 & 科技创新产业能力 & 数据分析能力 & 市场营销 & 市场推广执行能力 & 营销实践 \\
\hline \multirow{7}{*}{$\begin{array}{l}\text { 课程体 } \\
\text { 系 }\end{array}$} & 1 & 计算机基础 & \multirow{7}{*}{$\begin{array}{l}\text { 经济数学 I、宏观经济 } \\
\text { 学 } \\
\text { 经济数学 II、微观经济 } \\
\text { 学 } \\
\text { 统计学、会计学 } \\
\text { 消费者行为学、市场调 } \\
\text { 查与预测、财务管理 } \\
\text { 微积分 } \\
\text { 商业大数据分析与应 } \\
\text { 用 } \\
\text { 实训 }\end{array}$} & 管理学, 原理 & $\begin{array}{l}\text { 计算机图像处理技术基础 } \\
\text { (Photoshop) }\end{array}$ & 学院市场营销训练营 \\
\hline & 2 & 基础概念养成 & & 市场营销学、企业战略管理 & \multirow{4}{*}{$\begin{array}{l}\text { Photoshop } \\
\text { 高级应用 } \\
\text { 市场活动方案案例分析 } \\
\text { 动画高级应用、网页设计与 } \\
\text { 制作 } \\
\text { 商品美学、公关原理与实务 }\end{array}$} & 学院市场营销训练营 \\
\hline & 3 & 智能科技 & & \multirow{4}{*}{$\begin{array}{l}\text { 网络营销、电子商务概论 } \\
\text { 品牌管理与决策、组织行为 } \\
\text { 学 } \\
\text { 客户关系管理、商务谈判、 } \\
\text { 营销定位分析与决策、市场 } \\
\text { 营销案例分析 }\end{array}$} & & 跨学院市场营销训练营 \\
\hline & 4 & 云计算 & & & & 跨学院市场营销训练营 \\
\hline & 5 & & & & & 科技创新企业实训 \\
\hline & 6 & 人工智能（基础） & & & 新零售营销管理 & 科技创新企业实训 \\
\hline & 7 & $\begin{array}{l}\text { 人工智能企业营销 } \\
\text { 案例分析 } \\
\text { 论文与科技创新企 } 上\end{array}$ & & 人力资源管理、公司治理 & & 科技创新企业实训 \\
\hline
\end{tabular}

\section{5. 创建面向大湾区科技创新产业的应用型本科市场营 销教育组织和管理体系, 成立学院指导下的大湾区 科技创新产业市场营销咨询服务中心}

学院指导下的大湾区科技创新产业市场营销咨询服务 中心致力于为校友和在校市场营销学生之间搭建平台以帮 助他们寻找并发现志同道合的队友、合作伙伴及员工。具体 而言，该科技创新产业市场营销咨询中心有两大职责：一是 作为连接校友和学生的平台, 以促进科技创新产业的市场营 销导向资源利用与合作; 二是帮助校友和在校学生深入熟悉 科技创新产业的市场营销系统。[12]该中心设有常驻市场营 销导师或成功的市场营销者、职业顾问, 为学生提供市场营 销全过程指导和咨询。学生也可通过邮件的方式预约市场营 销导师，进行面对面交流或在线答疑。大湾区科技创新产业 市场营销咨询服务中心吸纳具有经验丰富的科技创新产业 市场营销咨询人员，吸纳具有科技创新产业能力营销专家和 技术专家, 从而扩大学院在科技创新产业市场营销的校友圈。

因此创建面向大湾区科技创新产业的应用型科技市 场营销教育组织和管理体系, 以全面促进科技创新产业的 市场营销实践，从而形成粤港澳大湾区科技创新产业市场 营销的人才培养生态系统。

\section{6. 多层次的营销比赛锻炼学生营销策划能力}

校内学生社团自组织的市场营销协会, 有效传播推广 市场营销文化。市场营销协会组织学生参与各类市场营销 比赛和实践活动, 是市场营销人才培养生态系统的重要组 成部分。

每年举办一次的全国高校市场营销大赛是深化教育 部“以能力和职业 $\mathrm{du}$ 发展为导向”的人才培养要求; 建立营
销实务教学、以赛促学的机制; 推动高等院校营销实践课 程体系和内容的改革; 引导和培养高校学生营销创新、策 划和应变能力; 增强和促进学生团队协作、主动创新的职 业素养及就业竞争力而举办的营销专业竞赛。

由教育部组织的“互联网+创新创业大赛”，也是市场 营销学生锤炼营销策划能力的绝佳平台, 激发学生营销策 划创造力, 推动赛事成果转化, 促进“互联网+”新业态形 成, 服务经济提质增效升级; 以创新引领创业、创业带动 就业, 推动高校毕业生更高质量创业就业。

此外学校还可以结合自身办学特点联合科技创新型 企业，由市场营销协会组织开展“粤港澳大湾区科技创新 型企业市场营销大赛”, 让学生在校内就能体验科技创新 型产业营销实践，强化科技创新型企业市场营销思维，有 针对性的吸引大湾区内匹配的科技创新型企业参与, 获奖 的同学获得心仪企业实习机会, 满足大湾区科技创新型企 业营销人才储备培养需求, 缓解应用型本科市场营销人才 万能膏药, 但无一专长的就业压力。

\section{7. 粤港澳三地应用型本科合作办学, 培养具有广府情 怀、国际视野的应用型营销人才}

今年, 个别港独势力的极端行为, 给祖国统一繁荣富 强、“一国两制”的治国理念带来不和谐的声音。广东是著 名侨乡, 拥有港澳同胞 365 万人, 海外华侨华人达 897 万人。 在海外居住的大量广府人, 是传承中华文化的重要纽带。 粤港澳高校联盟由中山大学率先倡议并于香港中文大学 和澳门大学共同发起, 迄今汇聚粤港澳三地 28 所高校, 包 括中山大学、华南理工大学等12所广东高校; 香港中文大 学、香港大学等9所香港高校; 澳门大学、圣若瑟大学等7 所澳门高校。中华人民共和国香港特别行政区政府教育局 局长吴克俭说, 建立人才高地, 不能单靠一个地区和一所 
学校, 需要多地多校共同努力, 优势互补, 粤港澳高校联 盟成立是三地教育合作发展的里程碑。广东省副省长蓝佛 安认为, 联盟致力于深化三地学生交流和科研合作、协同 创新, 携手打造“粤港澳一小时学术圈”。

在高校强强联合的基础上，进一步推广粤港澳三地应 用型本科营销人才培养合作的新型模式, 共同面对世界话 语体系下的大学竞争。加强高校学生的交流互访, 开展更 多的营销策划项目合作, 大型实训设施共享, 设立创新训 练营等形式为三地新型产业的了解和文化的融合带来更 大的平台。有利于培养具有广府情怀、国际视野的应用型 营销人才, 增进三地师生情谊。

积极与科技企业、粤港澳三地应用型本科高校合作办 学, 为粤港澳大湾区建设输送新型优秀应用型本科营销人 才, 实现学校、高新技术企业、学生三方共赢。

\section{5. 结论}

粤港澳大湾区培育的人才应该有自己的特色, 这个特 色就是：国际化, 数字化、创新型的人才。是故, 本区高 校应该创造这类人才在此萌芽茁壮。而且我们也要在大湾 区打造一个国际化的平台, 吸引世界各地的人才来此工作。 截至2018年底, 深圳港中大已引进知名教师280多位, 其 中包括诺贝尔奖得主 4 位, 图灵奖得主 2 位, 菲尔兹奖获得 者1位, 各国院士和国家级专家 30 多名。并逐渐落实在机 器人与人工智能、大数据与数据科学、未来智能网络、生 物信息学、新材料和能源科学、国际金融与物流、制药和 精准医学等领域组建世界级专家队伍, 正在面向国家及珠 三角地区战略性新兴产业发展需要, 打造国际化科技创新 平台, 完善学科建设。这也就是为此目的服务。大学要把 心思放在学校建设和人才发展上, 除此之外, 高校要想办 法、想点子为人才提供一个用武之地和良好的工作环境, 这样才能够把人才留住。推行和鼓励粤港澳大湾区高校科 研院所的高端人才在湾区内有序交流, 最大化落实人尽其 才、才尽其用的原则, 牢记各高校管理层的存在是为大学 服务、为人才服务、其目的在无私忘我地建设一流大学。

\section{致谢}

本研究受基金项目: 广州市哲学社会科学发展“十三 五”规划2020年度共建课题《广州市居民实物消费与体验 消费对幸福感的影响机制研究》(课题编号: 2020GZGJ210) 支持, 本研究承担所有文责。

\section{参考文献}

[1] 卓泽林,杨体荣.粤港澳大湾区高校集群建设的发展导向及 其路径 $[\mathrm{J}]$.教育发展研究.2019(11)。
[2] 余晖.协同共治:粤港澳大湾区高校智库发展机制创新 [J].苏 州大学学报(教育科学版).2019(02)。

[3] 杨军. 基于人力资本市场需求的应用型本科市场营销人才 培养模式[J].教育与职业,2015(25):87-89.

[4] 蒋文锋.大湾区内本科应用型营销人才培养模式的重构 [J]. 教科技和产业,2020(04)。

[5] 刘冰,刘崇磊,潘海生.地方高校“学训研赛”一体化人才培养 模式构建 [J].高等工程教育研究,2018(5):88-92.

[6] 卢莹. 基于CDIO理念的市场营销专业创新创业人才培养模 式探究 [J].教育科学论坛.2017(15)。

[7] 季红颖.高校市场营销专业创新型人才培养模式探析[J].科 技信息.2010(35)。

[8] 王慧.市场营销专业创新创业型人才培养模式研究 [J]. 知识 经济.2019(21)。

[9] 高维,刘国巍.产教融合视角下应用型本科市场营销专业人 才培养模式探析[J].教育观察,2018(15):68-70.

[10] 2019 年 粤 港澳大湾区人力资源白皮书 [EB/OL].(2019-08-01).www.mercer.com.cn.

[11] 粤 港 澳 大 湾 区 发 展 规 划 纲 要 [EB/OL].(2019-02-20).www.xinhuanet.com.

[12] 从世界 500 强榜单看四大湾区经济 [EB/OL].(2019-07-24).www.sohu.com.

[13] 《广深科技创新走廊规划》, 广东省政府, 2017-12-25

[14] http:/www.gov.cn/xinwen/2017-12/25/content_5250097.htm

[15] 广深科技创新走廊|构建“一廊十核多节点”. 腾讯-大粤网 [引用日期2018-02-07]。

[16] 打造广深科技创新走廊广深莞如何唱好“三城记”. 南方都 市报[引用日期2018-02-08]。

\section{作者简介}

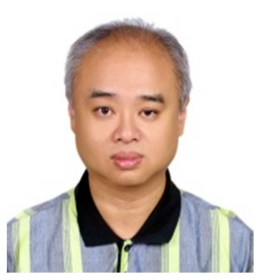

张哲彰 (1961 05) 男 中国台湾 暨南 大学博士研究生 副教授 主要研究方 向: 企业变革、跨文化管理; 现任职于 广州华商学院工商管理系副教授。
庄明杰 男 广东财经大学工商管理系学生。

王子玲 (1985-), 女, 海南海口人, 教师, 硕士研究 生, 主要研究方向: 教育改革、战略管理。 